LETTER TO JMG

\title{
Missense mutations in the $\beta$ strands of the single A-domain of matrilin-3 result in multiple epiphyseal dysplasia
}

\author{
G C Jackson, F S Barker, E Jakkula, M Czarny-Ratajczak, O Mäkitie, W G Cole, M J Wright, \\ S F Smithson, M Suri, P Rogala, G R Mortier, C Baldock, A Wallace, R Elles, L Ála-Kokko, \\ M D Briggs
}

J Med Genet 2004;41:52-59

M ultiple epiphyseal dysplasia (MED) is a relatively mild and clinically variable osteochondrodysplasia in which the hip and knee joints are most frequently affected. Both autosomal dominant and autosomal recessive forms of MED are recognised. The more severe forms of MED are often described as the "Fairbank type", whereas the milder cases are known as the "Ribbing type". However, this classification belies a much greater clinical spectrum in which characteristics such as radiographic features, age of onset, degree of lower limb deformity, stature, and long term morbidity such as osteoarthritis are extremely variable. ${ }^{1-4}$ It is therefore not surprising that MED is genetically heterogeneous, and to date mutations in six different genes have been shown to cause MED. ${ }^{56}$ Mutations in the genes encoding cartilage oligomeric matrix protein $(C O M P)$, the $\alpha 1, \alpha 2$, and $\alpha 3$ chains of type IX collagen (COL9A1, COL9A2, and COL9A3) and matrilin-3 (MATN3) all result in autosomal dominant MED, ${ }^{7-11}$ whereas specific mutations in the sulphate transporter 26A2 (SLC26A2 /DTDST) have been shown to result in an autosomal recessive form of MED. ${ }^{12}{ }^{13}$ Preliminary genotype-phenotype correlations have suggested that the more severe forms of autosomal dominant MED often result from COMP mutations, while the milder forms are more probably caused by mutations in the genes encoding type IX collagen or matrilin-3. ${ }^{14}{ }^{15}$ However, the number of patients available for comparative study, particularly those with type IX collagen and matrilin-3 defects, has remained too limited to date to allow any in depth correlations to be derived.

The matrilins are a four member family of extracellular matrix proteins; matrilin- 1 and -3 are specifically expressed in cartilaginous tissues, while matrilin- 2 and -4 have a wider pattern of expression in a variety of extracellular matrices including non-skeletal tissues. ${ }^{16}{ }^{17}$ Each member of the family comprise one or two von Willebrand factor A-like domains (A-domains), a variable number of EGF-like motifs and a coiled coil carboxyterminal domain. ${ }^{18}{ }^{19}$ A-domains are also found in various collagenous and non-collagenous extracellular matrix proteins, such as type VI collagen, the XII, XX, XIV, and XXI FACIT collagens, cochlin, vitrin (reviewed in Whittaker and Hynes $^{20}$ ), and WARP. ${ }^{21}$ Structurally, these domains are composed of around two hundred amino acids arranged into repeating $\alpha-\beta$ units in the classic Rossman fold, resulting in a central $\beta$ sheet core $(\beta A-\beta F)$ flanked by $\alpha$ helices $(\alpha 1-\alpha 7)$. A-domains are thought to mediate interactions with other proteins via the metal ion dependant adhesion site (MIDAS) motif and their involvement in oligomerisation, filamentous network formation, and cell adhesion and spreading has been reported. ${ }^{20} 2223$

We have previously shown that mutations in the matrilin-3 gene (MATN3) can result in mild to moderate forms of MED. ${ }^{10}$ To gain a better understanding of the role of matrilin3 in MED and to identify a range of disease causing mutations within this important structural protein, we

\section{Key points}

- Four novel mutations (A219D, I192N, T120M, and E134K) and one recurrent mutation (R121W) were identified in MATN3 in seven families with multiple epiphyseal dysplasia.

- All of the disease causing mutations are located within the $\beta$ sheet of the single A-domain of matrilin-3, which strongly suggests that they have a deleterious effect on the folding and/or function of matrilin-3.

- The R121W mutation is associated with a marked interfamilial variability in the radiographic phenotype of patients, suggesting that other genetic factors are acting to modify the severity of the multiple epiphyseal dysplasia phenotype in these patients.

screened MATN3 in an additional 50 unrelated individuals with MED. We now report the identification of four novel disease causing mutations (A219D, I192N, T120M, and E134K), one previously published mutation (R121W) and two non-synonymous polymorphisms (E252K and T303M) in nine unrelated families. All of the potential disease causing mutations are located within the central $\beta$ sheet region of the single A-domain of matrilin-3, suggesting that they influence the folding and/or function of this important domain.

\section{MATERIALS AND METHODS}

DNA was initially received in Manchester from 50 individuals affected with MED and then subsequently from other family members of those individuals with a suspected MATN3 mutation. In each case, a diagnosis of MED was suspected on the clinical and/or radiographic presentation of the proband. Furthermore, a disease causing mutation in specific exons of the COMP and type IX collagen genes had been previously excluded in these patients. Specifically, bi-directional sequencing of exons 8-19 of COMP, exons 8, 9, and 10 of COL9A1 and exons 2, 3, and 4 of COL9A2 and COL9A3 had been undertaken in patients referred in the UK $(n=12)$, whereas a combination of CSGE and direct sequence analysis had been used to exclude a mutation in all the exons encoding COMP and type IX collagen in patients referred via Toronto $(\mathrm{n}=20)$ and Poznan $(\mathrm{n}=18)^{11}$ (also CzarnyRatajczak et al; and J Kennedy et al, unpublished data). The University of Manchester ethics committee approved this study, and informed consent was obtained prior to the collection of blood samples.

Abbreviations: MED, multiple epiphyseal dysplasia 
The MATN3 and MATN1 genes were sequenced in each patient using genomic DNA as a template for PCR. Exons 1, 2, 3, and 4 of MATN3 and exons 2, 3, 5, and 6 of MATN1 were amplified as single DNA products, whereas exons 5, 6, 7, and 8 of MATN3 were amplified as a single chimeric DNA product by Meta-PCR (tables 1 and 2). ${ }^{24}$ PCR amplified DNA was either subjected to bi-directional sequencing or individual alleles were cloned and then sequenced.

The amino acid sequence of the A-domain from human matrilin-3 was used to probe the Research Collaboratory for Structural Bioinformatics (RCSB) consortium database. Sequences resulting from this search included the human von Willebrand factor $\mathrm{Al}$ and $\mathrm{A} 3$ domains and the integrin I-domain. The sequence with the highest homology was the I-domain from integrin $\alpha$ l (RCSB entry 1QC5) and this structure was used as the starting point for homology modelling. The secondary structural elements from the I-domain and the predicted secondary structure for the matrilin-3 A-domain (calculated using Predict Protein ${ }^{25}$ ) were overlaid on a sequence alignment and were used to improve the alignment manually. All molecular modelling was performed on an R10 $000 \mathrm{O} 2$ Silicon graphics workstation using InsightII programs (Accelrys Ltd, Cambridge, UK). The model of the matrilin-3 A-domain was built based on the coordinates of the I-domain. The domain was energy minimised using steepest descents followed by the conjugate gradient algorithm to convergence, removing bad steric and electrostatic contacts. The Protein Health module was used to check the integrity of the model using a Ramachandran plot, and to identify buried hydrophilic or exposed hydrophobic residues and close contacts.

\section{RESULTS}

\section{Clinical summary}

Clinical geneticists, orthopaedists, and/or radiologists with extensive experience in the diagnosis of skeletal dysplasias had examined the clinical history and appropriate $x$ rays of the families in which we identified a MATN3 mutation and confirmed the diagnosis of MED. The main clinical and radiographic features of each family are also summarised in table 3.

\section{Family 1}

The proband (III-2) presented at 4 with mild short stature and genu valgum. He is presently 12 years of age, has prominent genu valgum and complains of joint pain and stiffness. His height is now $93 \mathrm{~cm}(<3$ rd percentile) while his mother, who also has mild bilateral genu valgum, is $160 \mathrm{~cm}$ (25th percentile).

\section{Family 2}

The proband (III-1) is now 5 years old but was assessed at 2 years of age for possible hip dysplasia based on family history. Her father had been diagnosed with bilateral hip dysplasia at 8 years of age, and has undergone multiple surgeries. The proband's radiographs were consistent with MED but she has remained asymptomatic.

\section{Family 3}

At 6 years of age, the proband (II-1) complained of pain in the hips and knees and is now unable to walk medium to long distances. She is now 8 years old and has a height of $124 \mathrm{~cm}$ (75th percentile).

\section{Family 4}

The proband (IV-2) is now 5 years old but presented at 2 years with knee pain. At 5 years of age his height was $83 \mathrm{~cm}$ (10th percentile) and he has mild limb shortening.
Table 1 Primer sequences used to amplify individua MATN1 and MATN3 exons

\begin{tabular}{|c|c|c|c|}
\hline Gene & Exon & Primer sequences & $\begin{array}{l}\text { Product } \\
\text { size (bp) }\end{array}$ \\
\hline \multirow[t]{3}{*}{ MATN3 } & 1 & $\begin{array}{l}\text { (F) 5'-GTTCTGCCGCTGGAATG-3' } \\
\text { (R) 5'-CACATGAGTGATATTGGGCATC-3' }\end{array}$ & 603 \\
\hline & 2 & $\begin{array}{l}\text { (F) 5'-CTAATTGTGGTCTGATCATTG-3' } \\
\text { (R) } 5^{\prime} \text {-GTGGAAGCAAAGACTGACC-3' }\end{array}$ & 629 \\
\hline & $3-4$ & $\begin{array}{l}\text { (F) } 5^{\prime} \text {-GACATGGGAGACGGTATCTGA-3' } \\
\text { (R) } 5^{\prime} \text {-CTICCATCACCGGGTAGGTA-3' }\end{array}$ & 1465 \\
\hline \multirow[t]{4}{*}{ MATNI } & 2 & $\begin{array}{l}\text { (F) 5'-TGTCTCTGCTCTCTGCCTTA-3' } \\
\text { (R) 5'-AGCCTCCAAACAGCAGCATCC-3' }\end{array}$ & 520 \\
\hline & 3 & $\begin{array}{l}\text { (F) } 5^{\prime} \text {-TCAGCCTCCTCTCCTGGAC-3' } \\
\text { (R) } 5^{\prime} \text {-CCCGGCACTGACATCTATC-3' }\end{array}$ & 279 \\
\hline & 5 & $\begin{array}{l}\text { (F) 5'-ATCCTCAGCACAGAGCTGG-3' } \\
\text { (R) 5'-AGTTGGGCTATACCCGTGTG-3' }\end{array}$ & 587 \\
\hline & 6 & $\begin{array}{l}\text { (F) } 5^{\prime} \text {-CCCATGTCCAGCCTTACTTC- } 3^{\prime} \\
\text { (R) } 5^{\prime} \text {-CTGCAAATCCCATCAATG-3 } 3^{\prime}\end{array}$ & 230 \\
\hline
\end{tabular}

\section{Family 5}

The proband (IV-2) is currently 18 years old. He presented with knee pain and valgus deformity at 2 years. At 14 years, the proband was $163 \mathrm{~cm}$ tall (50th percentile). His affected father is $178 \mathrm{~cm}$ (50th-75th percentile) tall and has had hip pain and valgus deformity of the knees.

\section{Family 6}

The proband (II-5) presented with progressive genu valgum at 5 years of age and became symptomatic with knee and ankle pain at 11 years. Bilateral distal femoral varus osteotomies and tibial osteotomy were performed at 13 and 15 years respectively. His affected brother has had genu valgum and knee pain since the age of 5 years. At 1 year his height was $128 \mathrm{~cm}$ (3rd-10th percentile).

\section{Family 7}

The proband (III-1) is a 5 year old girl with a height of $110 \mathrm{~cm}$ (25th percentile), who has had knee pain since the age of 2 years. Her radiographs at 2 and 4 years showed delayed ossification of the proximal femoral epiphyses consistent with MED.

Table 2 Primers used to amplify MATN3 exons 5-8 as a Meta-PCR fragment

\begin{tabular}{|c|c|c|}
\hline $\begin{array}{l}\text { PCR } \\
\text { step }\end{array}$ & Primer sequences & $\begin{array}{l}\text { Product } \\
\text { size } \\
\text { (bp) }\end{array}$ \\
\hline Primary & 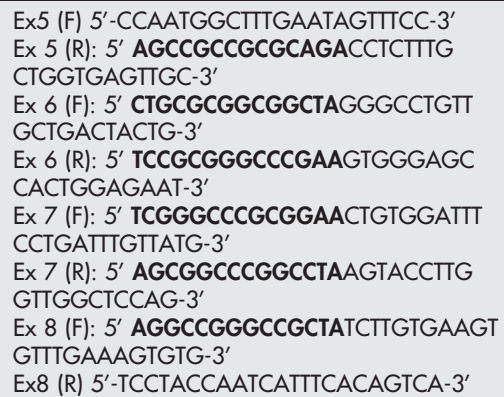 & $\mathrm{N} / \mathrm{A}$ \\
\hline $\begin{array}{l}\text { Secon- } \\
\text { dary }\end{array}$ & $\begin{array}{l}\text { ROUND 2(F): 5'- (GTAGCGCGACGGCCAGT) } \\
\text { GCTGCAAATAAGGTITCTATCCTG-3' } \\
\text { ROUND 2(R): 5'-(CAGGGCGCAGCGATGAC) } \\
\text { TTAAGTACACCAAGCTGTCCACAT-3' }\end{array}$ & 1125 \\
\hline
\end{tabular}

Unique linker sequences for META-PCR are shown in bold and universal primer sequences, which are used for sequencing of the chimeric DNA products are shown in parenthesises 
Table 3 Main clinical and radiographic features of families with a MATN3 mutation

\begin{tabular}{|c|c|c|c|c|c|c|c|}
\hline \multirow[b]{2}{*}{ Family } & \multirow[b]{2}{*}{ Mutation } & \multirow{2}{*}{$\begin{array}{l}\text { Age at diagnosis and } \\
\text { presenting symptoms }\end{array}$} & \multirow{2}{*}{$\begin{array}{l}\text { Short } \\
\text { stature }\end{array}$} & \multicolumn{4}{|c|}{ Prominent radiographic features of proband } \\
\hline & & & & Knees & Hips & Spine & Hands \\
\hline 1 & A219D & $\begin{array}{l}4 \text { years (III-1): mild short } \\
\text { stature and genu valgum }\end{array}$ & Yes & $\begin{array}{l}\text { Small epiphyses with regular } \\
\text { contours and genu valga at } \\
10 \text { years of age }\end{array}$ & $\begin{array}{l}\text { Coxa vara, small } \\
\text { epiphyses, short and } \\
\text { broad femoral necks } \\
\text { at } 10 \text { years of age }\end{array}$ & $\begin{array}{l}\text { Irregular ossification of } \\
\text { the upper and lower } \\
\text { end plates at } 7 \text { years } \\
\text { of age }\end{array}$ & $\begin{array}{l}\text { No brachydactyl } \\
\text { but small carpal } \\
\text { bones at } 4 \text { years } \\
\text { of age }\end{array}$ \\
\hline 2 & $1192 \mathrm{~N}$ & $\begin{array}{l}2 \text { years (III-2), } 8 \text { years } \\
\text { (II-2), } 10 \text { years (II- }-1) \text {, } \\
31 \text { years (1-1): bilateral } \\
\text { hip dysplasia }\end{array}$ & No & $\begin{array}{l}\text { Epiphyses small and irregular } \\
\text { in contour at } 6 \text { years of age }\end{array}$ & $\begin{array}{l}\text { Small epiphyses, } \\
\text { short and broad } \\
\text { femoral necks at } \\
6 \text { years of age }\end{array}$ & $\begin{array}{l}\text { Vertebral bodies have } \\
\text { a slightly reduced } \\
\text { height and an oval } \\
\text { shape at } 6 \text { years of age }\end{array}$ & $\begin{array}{l}\text { Mild metaphyseal } \\
\text { changes at } \\
6 \text { years of age }\end{array}$ \\
\hline 3 & T120M & $\begin{array}{l}6 \text { years: pain in the } \\
\text { hips and knees }\end{array}$ & No & $\begin{array}{l}\text { Small epiphyses with irregular } \\
\text { contours and vertical } \\
\text { metaphyseal striations at } \\
8 \text { years of age }\end{array}$ & Not available & $\begin{array}{l}\text { Irregular ossified end } \\
\text { plates at } 8 \text { years of } \\
\text { age }\end{array}$ & $\begin{array}{l}\text { Relatively normal } \\
\text { at } 8 \text { years of age }\end{array}$ \\
\hline 4 & E134K & 2 years: knee pain & Yes & Not available & Not available & Not available & Not available \\
\hline 5 & R121W & $\begin{array}{l}2 \text { years: knee pain and } \\
\text { valgus deformity }\end{array}$ & No & $\begin{array}{l}\text { Relatively normal at } 14 \text { years } \\
\text { of age }\end{array}$ & $\begin{array}{l}\text { Small epiphyses and } \\
\text { broad femoral necks } \\
\text { at } 9 \text { years of age }\end{array}$ & $\begin{array}{l}\text { Normal at } 14 \text { years } \\
\text { of age }\end{array}$ & $\begin{array}{l}\text { Flattened distal } \\
\text { radial epiphysis at } \\
14 \text { years of age }\end{array}$ \\
\hline 6 & $\mathrm{R} 121 \mathrm{~W}$ & $\begin{array}{l}5 \text { years (II-1 and II-5): } \\
\text { knee pain and } \\
\text { progressive genu valga }\end{array}$ & Yes & $\begin{array}{l}\text { Small epiphyses with irregular } \\
\text { contours at } 7 \text { years of age }\end{array}$ & $\begin{array}{l}\text { Coxa vara, small } \\
\text { epiphyses and short } \\
\text { moral necks at } \\
7 \text { years of age }\end{array}$ & $\begin{array}{l}\text { Wedge shaped lumbar } \\
\text { vertebral bodies at } \\
7 \text { years of age }\end{array}$ & Not available \\
\hline 7 & $\mathrm{R} 121 \mathrm{~W}$ & $\begin{array}{l}2 \text { years (III- }-1), 15 \text { years } \\
\text { (II-2), } 10 \text { years (II- } 1) \text {, } \\
9 \text { years (I-1): knee pain } \\
\text { and waddling gait }\end{array}$ & No & $\begin{array}{l}\text { Relatively normal at } 15 \text { years } \\
\text { of age }\end{array}$ & $\begin{array}{l}\text { Very flat epiphyses } \\
\text { and short femoral } \\
\text { necks at } 15 \text { years of } \\
\text { age }\end{array}$ & Not available & Not available \\
\hline
\end{tabular}

A

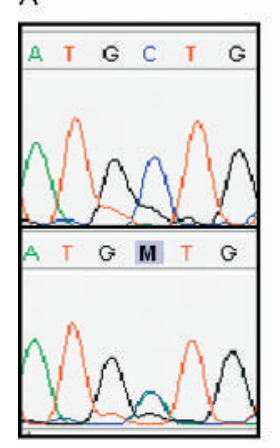

G

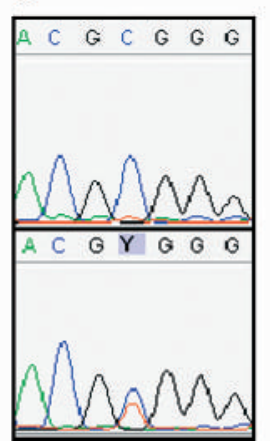

B

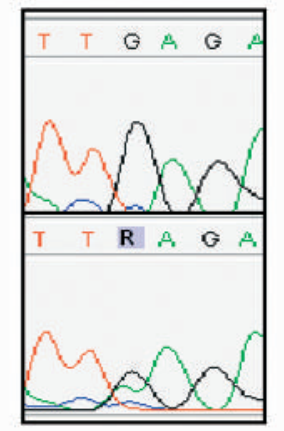

$\mathrm{C}$

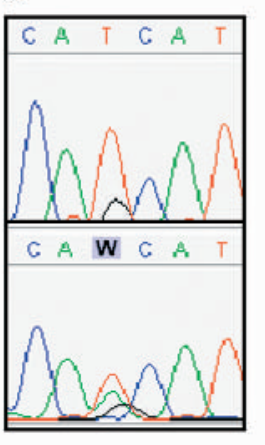

D

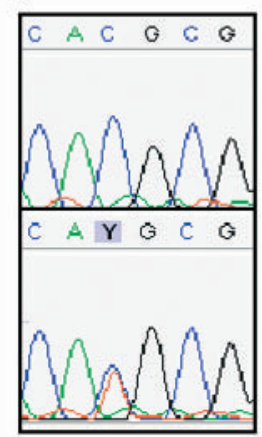

$\mathrm{E}$

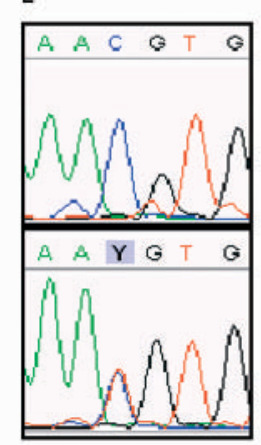

$\mathrm{F}$

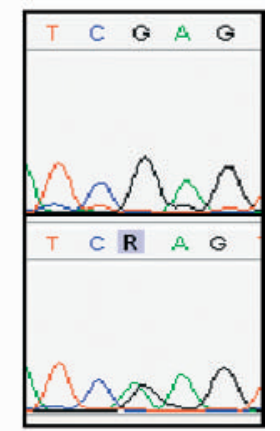

$\mathrm{H}$

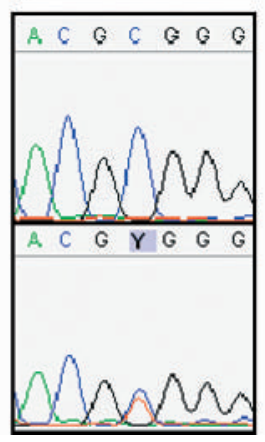

1

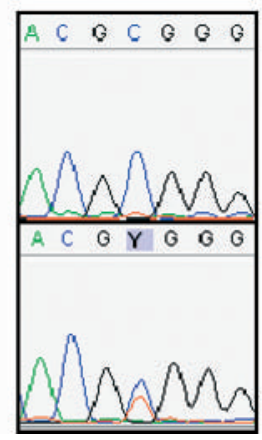

$\mathrm{J}$

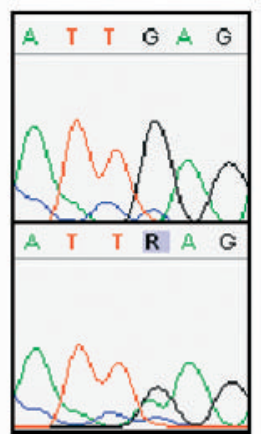

K

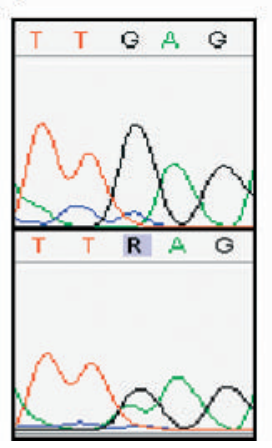

Figure 1 DNA sequence analysis of exon 2 and exon 3 of MATN3 in nine probands with MED. The top panel shows a normal sequence trace for comparison, while the bottom panel shows the sequence trace from each proband with a missense mutation. $(A, B)$ Individual III- 1 in family 1 , heterozygous at nt $656(\mathrm{c} / \mathrm{c} \rightarrow \mathrm{c} / \mathrm{a})$ and $\mathrm{nt} 754(\mathrm{~g} / \mathrm{g} \rightarrow \mathrm{g} / \mathrm{a})$; (C) individual III-2 in family 2, heterozygous at nt 575 (t/t $\rightarrow \mathrm{t} / \mathrm{a})$; (D) individual II-1 in family 3 heterozygous at nt $359(\mathrm{c} / \mathrm{c} \rightarrow \mathrm{c} / \mathrm{t})$; (E) individual II- 1 in family 3, heterozygous at nt $908(\mathrm{c} / \mathrm{c} \rightarrow \mathrm{c} / \mathrm{t})$; (F) individual IV-2 in family 4 , heterozygous at nt $400(\mathrm{~g} / \mathrm{g} \rightarrow \mathrm{g} / \mathrm{a}) ;(\mathrm{G})$ individual IV-2 in family 5, heterozygous at nt $361(\mathrm{c} / \mathrm{c} \rightarrow \mathrm{c} / \mathrm{t}) ;(\mathrm{H})$ individual II-5 in family 6 , heterozygous at nt $361(\mathrm{c} / \mathrm{c} \rightarrow \mathrm{c} / \mathrm{t})$; (I) individual II-1 in family 7 , heterozygous at nt $361(\mathrm{c} / \mathrm{c} \rightarrow \mathrm{c} / \mathrm{t}) ;(\mathrm{I})$ individual II-1 in family 8 , heterozygous at $\mathrm{nt} 754(\mathrm{~g} / \mathrm{g} \rightarrow \mathrm{g} / \mathrm{a})$; $(\mathrm{K})$ individual II-2 in family 9, heterozygous at nt $754(\mathrm{~g} / \mathrm{g} \rightarrow \mathrm{g} / \mathrm{a})$. $R$, guanine or adenine (purine); $Y$, cytosine or thymine (pyrimidine); $M$, adenine or cyłosine; W, adenine or thymine. 


\begin{tabular}{|c|c|c|c|}
\hline Proband & Nucleotide change & Exon & $\begin{array}{l}\text { Predicted protein } \\
\text { change }\end{array}$ \\
\hline \multirow[t]{2}{*}{1} & nt $656 c / c \rightarrow c / a$ & 2 & A219D \\
\hline & nt $754 \mathrm{~g} / \mathrm{g} \rightarrow \mathrm{g} / \mathrm{a}$ & 2 & E252K \\
\hline 2 & nt $575 \mathrm{t} / \mathrm{t} \rightarrow \mathrm{t} / \mathrm{a}$ & 2 & $1192 \mathrm{~N}$ \\
\hline \multirow[t]{2}{*}{3} & nt $359 \mathrm{c} / \mathrm{c} \rightarrow \mathrm{c} / \mathrm{t}$ & 2 & $\mathrm{~T} 120 \mathrm{M}$ \\
\hline & nt $908 \mathrm{c} / \mathrm{c} \rightarrow \mathrm{c} / \mathrm{t}$ & 3 & T303M \\
\hline 4 & nt $400 \mathrm{~g} / \mathrm{g} \rightarrow \mathrm{g} / \mathrm{a}$ & 2 & E134K \\
\hline 5 & nt $361 \mathrm{c} / \mathrm{c} \rightarrow \mathrm{c} / \mathrm{t}$ & 2 & $\mathrm{R} 121 \mathrm{~W}^{*}$ \\
\hline 6 & nt $361 \mathrm{c} / \mathrm{c} \rightarrow \mathrm{c} / \mathrm{t}$ & 2 & $\mathrm{R} 121 \mathrm{~W}^{*}$ \\
\hline 7 & nt $361 \mathrm{c} / \mathrm{c} \rightarrow \mathrm{c} / \mathrm{t}$ & 2 & $\mathrm{R} 121 \mathrm{~W}^{*}$ \\
\hline 8 & nt $754 \mathrm{~g} / \mathrm{g} \rightarrow \mathrm{g} / \mathrm{a}$ & 2 & E252K \\
\hline 9 & nt $754 \mathrm{~g} / \mathrm{g} \rightarrow \mathrm{g} / \mathrm{a}$ & 2 & E252K \\
\hline
\end{tabular}

\section{Identification of mutations in MATN3}

DNA sequence analysis identified seven different missense mutations in nine unrelated probands. Six of these mutations were novel and one had been previously reported to cause MED (fig 1, table 4).

\section{Family 1}

The proband in family 1 (fig 2; family 1 , individual III-1) was heterozygous for two nucleotide changes in exon 2 of MATN3. The first change was a $\mathrm{C} \rightarrow \mathrm{A}$ transversion at nucleotide 656 , which is predicted to result in an A219D substitution (fig 1A, table 4), and sequence analysis of DNA from his affected mother and maternal grandmother confirmed that they were also heterozygous for this change. The second change was a
$\mathrm{G} \rightarrow \mathrm{A}$ transition at nucleotide 754 , which is predicted to result in an E252K substitution (fig 1B, table 4). Sequence analysis of DNA from his mother and maternal grandmother showed the absence of this change (data not shown). Sequencing of individual MATN3 alleles from the proband demonstrated that the two changes were on different alleles. By implication, this suggested that the unaffected father carried the E252K change, but in the absence of a DNA sample this could not be confirmed directly.

\section{Family 2}

The proband (fig 2; family 2, individual III-2,) was heterozygous for a $\mathrm{T} \rightarrow \mathrm{A}$ transversion at nucleotide 575 , which is predicted to result in an I192N substitution (fig lC, table 4). Sequence analysis of DNA from her affected father confirmed that he was also heterozygous for this change, whereas analysis of DNA from her unaffected mother and unaffected brother confirmed that they did not have the mutation (data not shown). Interestingly, unaffected individuals II-3 and III- 1 in family 2 (fig 2 ) were also heterozygous for the $\mathrm{G} \rightarrow \mathrm{A}$ transition at nucleotide 754 (E252K) originally identified in individual III- 1 of family 1 .

\section{Family 3}

The proband (fig 2; family 3, individual II-1) was heterozygous for a $\mathrm{C} \rightarrow \mathrm{T}$ transition at nucleotide 359 (in exon 2) and a $\mathrm{C} \rightarrow \mathrm{T}$ transition at nucleotide 908 (in exon 3), which are predicted to result in T120M and T303M substitutions respectively (fig $\mathrm{ID}, \mathrm{E}$ and table 4). Analysis of DNA from her apparently unaffected mother demonstrated the presence of T120M but not T303M. Unfortunately, it was not possible to examine DNA from the father but it seems likely that he carries the $\mathrm{T} 303 \mathrm{M}$ change.
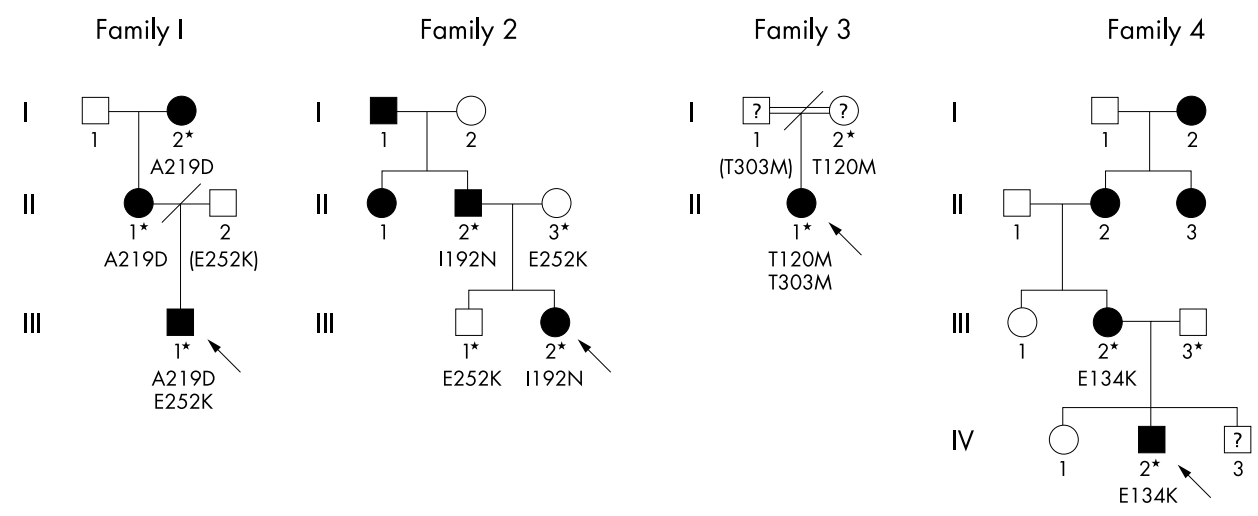

Family 5

(n)
Family 6

।

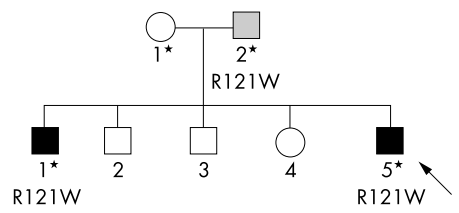

Family 7

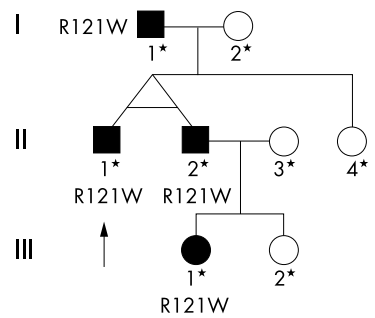

Family 8

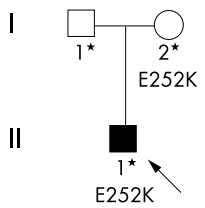

Family 9

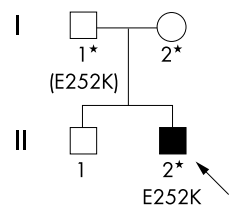

Figure 2 Pedigrees of the nine families with MED in which missense mutations were identified in the proband. The proband is indicated with an arrow and DNA sequence analysis was performed on those family members marked with an asterisk. Missense mutations that we identified in MATN3 are shown below the relevant family member. 


\section{Family 4}

The proband (fig 2; family 4, individual IV-2) was heterozygous for a $\mathrm{G} \rightarrow \mathrm{A}$ transition at nucleotide 400 , which is predicted to result in an E134K substitution (fig $1 \mathrm{~F}$, table 4). Analysis of DNA from his affected mother confirmed that she was also heterozygous for this change, whereas analysis of DNA from his unaffected father confirmed that he did not have the mutation (data not shown).

\section{Family 5}

The proband (fig 2; family 5, individual IV-2) was heterozygous for a $\mathrm{C} \rightarrow \mathrm{T}$ transition at nucleotide 361, which is predicted to result in a R121W substitution (fig lG, table 4). Analysis of DNA from his affected father confirmed that he was also heterozygous for this change, whereas analysis of DNA from his unaffected mother and brother confirmed that they did not have the mutation (data not shown). We have previously identified this missense mutation in one other family with MED, ${ }^{10}$ and in this study we identified two other families (families 6 and 7) that had the same mutation.

\section{Family 6}

This proband (fig 2; family 6, individual II-5) was also heterozygous for a $\mathrm{C} \rightarrow \mathrm{T}$ transition at nucleotide 361 predicted to result the R121W substitution (fig $1 \mathrm{H}$, table 4). Analysis of DNA from his affected brother and his apparently unaffected father demonstrated that they were also heterozygous for this change, whereas analysis of DNA from his unaffected mother confirmed that she did not have the mutation (data not shown). A re-evaluation of the clinical status of the father, who is now in his fifties, showed mild varus deformity of the knees, while radiographs showed bilateral shortening and broadening of the femoral necks with a coxa vara deformity and narrowed articular space, findings consistent with MED.

\section{Family 7}

The proband (fig 2; family 7, individual II-1) was heterozygous for a $\mathrm{C} \rightarrow \mathrm{T}$ transition at nucleotide 361 predicted to result an R121W substitution (fig II, table 4). Analysis of DNA from his affected twin brother, father, and niece confirmed that they were also heterozygous for this change, whereas analysis of DNA from his unaffected mother, sister, sister-in-law, and niece confirmed that they did not have the mutation (data not shown).

\section{Families 8 and 9}

The probands in these two families (fig 2; family 8, individual II- 1 and family 9, individual II-2) were both heterozygous for a $\mathrm{G} \rightarrow \mathrm{A}$ transition at nucleotide 754 , which is predicted to result in an E252K substitution (fig I, J and IK respectively; table 4). Analysis of the unaffected parents of the proband in family 8 demonstrated that the mother was also heterozygous for this change, whereas the father did not have the change. Analysis of the unaffected parents of proband 9 demonstrated that the mother did not have the change, suggesting that the father did carry the E252K change. This change was also identified in the proband in family 1 and in unaffected individuals of family 2 .

\section{MED mutations cluster in exon 2 of MATN3}

Following a comprehensive mutation screen of MATN3 we identified seven different missense mutations in nine unrelated families with MED (table 4). Five of these changes (A219D, I192D, T120M, T303M, and E134K) were unique to a single family, one change (R121W) had previously been reported to cause $\mathrm{MED},{ }^{10}$ and one change (E252K) was identified in unaffected members of four families. Analysis of 50 unrelated individuals without chondrodysplasia failed to identify the A219D, I192D, T120M, and E134K missense mutations in these control samples. The T303M change identified in family 3 and the E252K change identified in affected and unaffected members of families 1, 2, 8, and 9 were also identified in unrelated controls and have allele frequencies of $0.011(\mathrm{n}=182$ alleles $)$ and $0.024(\mathrm{n}=418$ alleles) respectively ( $\mathrm{J}$ Loughlin, personal communication). These data, supported by the fact that each of the four changes was unique to one family (and also was not present in the other 49 unrelated probands), strongly suggest that A219D, I192D, T120M, and E134K are novel disease causing mutations. Furthermore, all of the disease causing mutations that we have now identified in MATN3 cluster within exon 2 and affect residues within the conserved $\beta$ strands of the single A-domain of matrilin-3 (fig 3).

\section{Haplotype analysis in families 5, 6, and 7}

We considered the possibility that the Rl21W mutation, which we identified in families 5 and 7 (both from Poland) and a Belgian family previously reported, ${ }^{10}$ was a common ancestral mutation. Family 6 (also R121W) were originally from Vietnam and therefore thought unlikely to share a common ancestry with the three families from Northern Europe. During the course of this study, we identified five synonymous polymorphisms, which allowed us to investigate this observation further (table 5). Haplotype analysis demonstrated that the R121W mutation in the family from Belgium was not derived from a common ancestral haplotype shared by either family 5 or 7 (both from Poland) as the proband in the Belgium family did not have a MATN3 allele in common with the probands from families 5 and 7 (data not shown). Unfortunately we were unable to confirm that the mutation in the two families from Poland was not an ancestral mutation.

\section{MED mutations are not found in the equivalent domains of matrilin-1}

The precise location of MATN3 mutations in the exon encoding the A-domain of matrilin-3, together with the finding that matrilin-3 can form hetero-oligomers with matrilin-1 in cartilage, ${ }^{17} 26$ led us to hypothesise that mutations in the exons encoding the A domains of matrilin-1 might be a potential cause of MED. We therefore screened for a mutation in the four exons encoding the two A domains of matrilin-1 (exons 2, 3, 5, and 6) in the remaining 43 unrelated MED patients in which we had not identified a MATN3 mutation. DNA sequence analysis of these four exons identified two synonymous polymorphisms but no missense mutations (table 5).

\section{DISCUSSION}

A role for MATN3 mutations in the initiation and progression of MED was originally discerned on the basis of different missense mutations found in two families with MED. ${ }^{10}$ In this follow up study we have sequenced all eight exons of MATN3 in a further 50 patients with MED and identified four novel missense mutations, a previously published mutation and two non-synonymous polymorphisms. Each of the four novel mutations (A219D, I192N, T120M, and E134K), and the previously described mutation (R121W) are located within the $\beta$ sheet region of the single A domain of matrilin-3 (fig 4A, B). We have now found the Rl21W mutation in four out of nine families in which MATN3 mutations have been identified (3/7 in this study and $1 / 2$ in Chapman et $\mathrm{l}^{10}$ ). Furthermore, they all result from the same $\mathrm{C} \rightarrow \mathrm{T}$ transition at nucleotide $36 \mathrm{l}$, which is located at a $\mathrm{CpG}$ dinucleotide and may therefore be a 'hot-spot' for MATN3 mutations. Although it is highly likely that the A219D, I192D, T120M, R121W, and E134K changes are all disease causing, it 
A

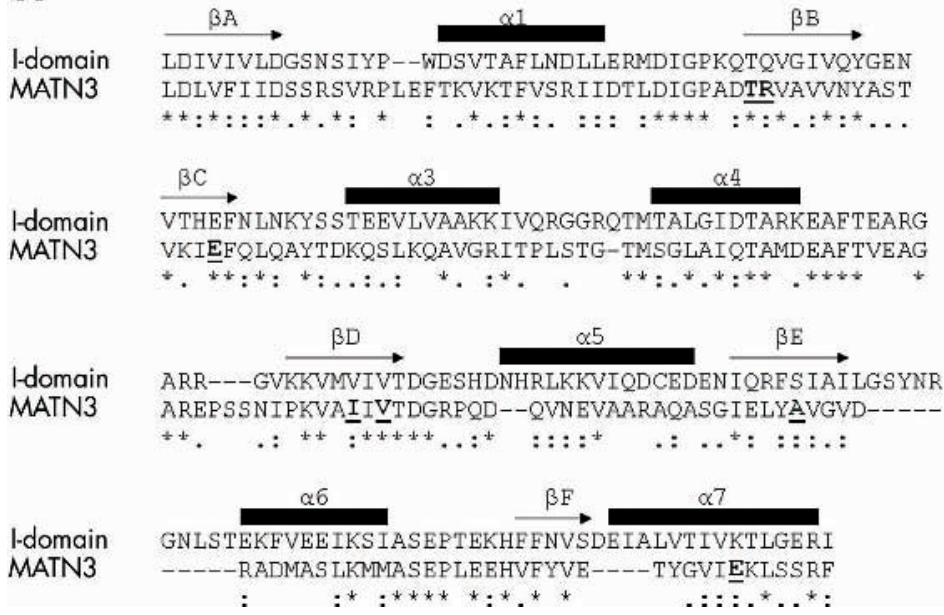

LDIVIVLDGSNSIYP--WDSVTAF LNDLLERMDIGPKOTOVGIVOYGEN LDLVF I IDSSRSVRPLEFTKVKT FVSR I IDT LDIGPADTRVAVVNYAST

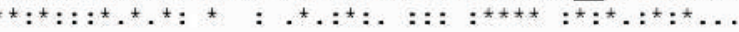

VTHEFNLNKYS STEEVLVAAKKIVQRGGRQTMTALGIDTARKEAFTEARG VKIEFQLQAYTDKQSLKQAVGRITPLSTG-TMSGLAIQTAMDEAFTVEAG

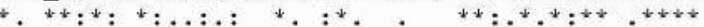

I-domain

ARR---GVKKVMVIVTDGESHDNHRLKKVIQDCEDEN IORFS IAI LGSYNR AREPSSNIPKVAI IVTDGRPOD--OVNEVAARAOASGIELYAVGVD----

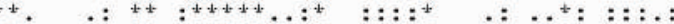

I-domain
B

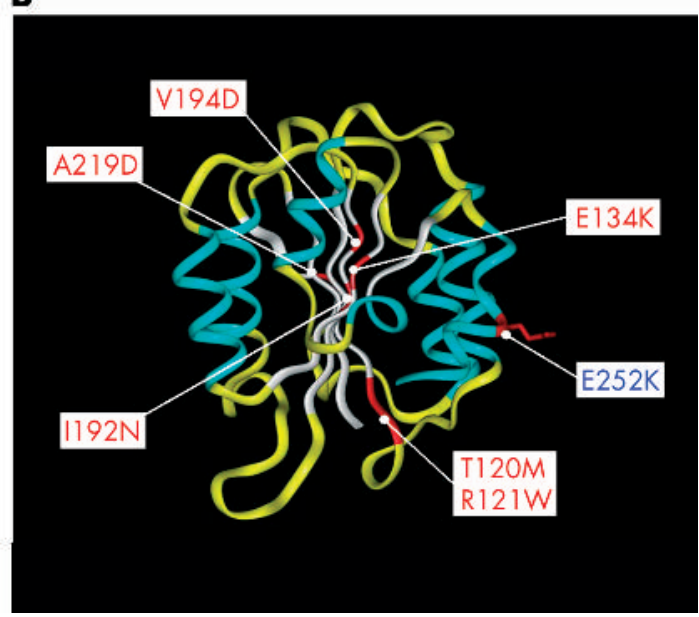

Figure 3 Sequence alignment and homology model of the A-domain of matrilin-3. Top, sequence alignment of the matrlin-3 A-domain with the Idomain from integrin $\alpha 1$ was performed using ClustalW and identical (*), conserved (:) and semi-conserved (.) residues are shown. An arrow indicates the $\beta$ strands while the $\alpha$ helices are filled boxes. Mutations are shown bold and underlined. Bottom, homology model of the matrilin- $3 \mathrm{~A}$-domain based on the known structure of the I domain from integrin $\alpha 1$. The $\alpha$-helices are shown in blue and the $\beta$ strands are shown in grey. The locations of disease causing mutations in the $\beta$ strands are indicated in red (T120M, R121W, E134K and A219D, R121W, and V194D from Chapman ef al), ${ }^{10}$ while the non-synonymous polymorphism (E252K) is also shown in the $\alpha-7$ helix (blue).

will require further biomolecular studies to demonstrate that they do indeed have a structural and/or functional affect on matrilin-3.

MED mutations have now been identified in four of the six $\beta$ strands of the matrilin-3 A-domain ( $\beta \mathrm{B}, \beta \mathrm{C}, \beta \mathrm{D}$, and $\beta \mathrm{E})$ and the precise location of these mutations in the highly conserved $\beta$ strands implies that the folding, secretion, and therefore the function of the A-domain of matrilin-3 might be compromised. By comparison, a missense mutation (G1679E) in the $\beta B$ strand of the N2 A-domain of the $\alpha 3(\mathrm{VI})$ chain of type VI collagen has been identified in a patient with Bethlem myopathy. ${ }^{27}$ Recombinant expression of this mutation in vitro demonstrated that the abnormal protein was rapidly degraded within the cells, ${ }^{28}$ thereby confirming the importance of the $\beta$ strands in the folding of A-domains. We hypothesise that the MATN3 mutations that we have identified in patients with MED act through either a dominant negative or dominant interference mechanism in a manner analogous to that of the A-domain mutation in Bethlem myopathy. However it will require extensive biochemical and biophysical analysis of mutant matrilin-3 in vitro and an in depth study of pathological tissues in vivo before the disease mechanism is completely understood in this form of MED.

During the course of this study, we also identified two nonsynonymous polymorphisms, namely E252K and T303M,

Table 5 Allele frequencies of synonymous SNPs identified in MATN3 and MATN1

\begin{tabular}{llll}
\hline $\begin{array}{l}\text { Nucleotide } \\
\text { (codon) }\end{array}$ & Exon & $\begin{array}{l}\mathrm{Nt} \\
\text { change } \% \text { (n) of alleles }\end{array}$ \\
\hline MATN3 & & & \\
$447(149)$ & 2 & $\mathrm{~T} \rightarrow \mathrm{C}$ & $37.3(47 / 129) \mathrm{T}, 62.7(79 / 126) \mathrm{C}$ \\
$625(205)$ & 2 & $\mathrm{~A} \rightarrow \mathrm{G}$ & $37.3(47 / 126) \mathrm{A}, 62.7(79 / 126) \mathrm{G}$ \\
$909(303)$ & 3 & $\mathrm{G} \rightarrow \mathrm{A}$ & $78(78 / 100) \mathrm{G}, 22(22 / 100) \mathrm{A}$ \\
IVS7+24 & - & $\mathrm{C} \rightarrow \mathrm{G}$ & $56(56 / 100) \mathrm{C}, 44(44 / 100) \mathrm{G}$ \\
IVS7-4 & - & $\mathrm{C} \rightarrow \mathrm{T}$ & $78(78 / 100) \mathrm{C}, 22(22 / 100) \mathrm{T}$ \\
MATN1 & & & \\
1551 (345) & 5 & $\mathrm{~T} \rightarrow \mathrm{C}$ & $56.60(111 / 196) \mathrm{T}, 43.40(85 / 196) \mathrm{C}$ \\
1764 (416) & 6 & $\mathrm{G} \rightarrow \mathrm{A}$ & $67.50(143 / 212) \mathrm{G}, 32.50(96 / 212) \mathrm{A}$ \\
\hline Nt, Nucleotide & & \\
\hline
\end{tabular}

located in the A-domain and EGF repeats respectively. We have demonstrated that on its own E252K, which was identified in a number of unaffected family members, does not cause MED. This observation is supported in part by its location in the $\alpha 7$ helical region (fig $4 \mathrm{~A}, \mathrm{~B}$ ), where it is postulated to have a less deleterious effect on the structure of the A-domain. Based on the intra-familial variability in family 1, we hypothesise that E252K may play a role in modifying the phenotypic severity of MED in this family. The proband, who had both the A219D and E252K changes, has short stature, whereas his mildly affected mother and grandmother, both carrying only the A219D change, had relatively normal height. In contrast to E252K, the T303M change lies within the first EGF repeat of matrilin-3 (numbered from the $\mathrm{N}$ terminus) and is therefore the only non-synonymous change that we identified outside of the A-domain. In family 3, the proband was a compound heterozygote (T120M/T303M) and we initially considered the possibility that this might represent a recessive form of MED. However, the location of the T120M mutation adjacent to the previously identified Rl21W substitution in the $\beta \mathrm{B}$ strand strongly suggests that it is disease causing (fig 4A, B). We have been unable to re-examine the clinical status of the proband's mother, but the apparent lack of a clinical manifestation in the mother may represent misdiagnosis; somatic mosaicism or incomplete penetrance, the latter feature, in addition to spontaneous improvement in symptoms, has been attributed to a mutation at the neighbouring residue (R121W) in family 6 (this study) and patient DL of family B (in Chapman et $a l^{10}$ ). We therefore suggest that the MED phenotype in the proband is due to the Tl20M mutation, but a role for $\mathrm{T} 303 \mathrm{M}$ in increasing the severity of the phenotype in the proband cannot be excluded.

In addition to modifying the severity of the MED phenotype it is also possible that on their own the E252K and $\mathrm{T} 303 \mathrm{M}$ changes may confer susceptibility to more common diseases such as Legg-Calve-Perthés disease or generalised osteoarthritis. Indeed, the T303M change has recently been reported to confer susceptibility to hand osteoarthritis in the Icelandic population. ${ }^{29}$ However, it should be noted that only a small proportion of hand OA in the patient cohort that was studied is attributable to the 

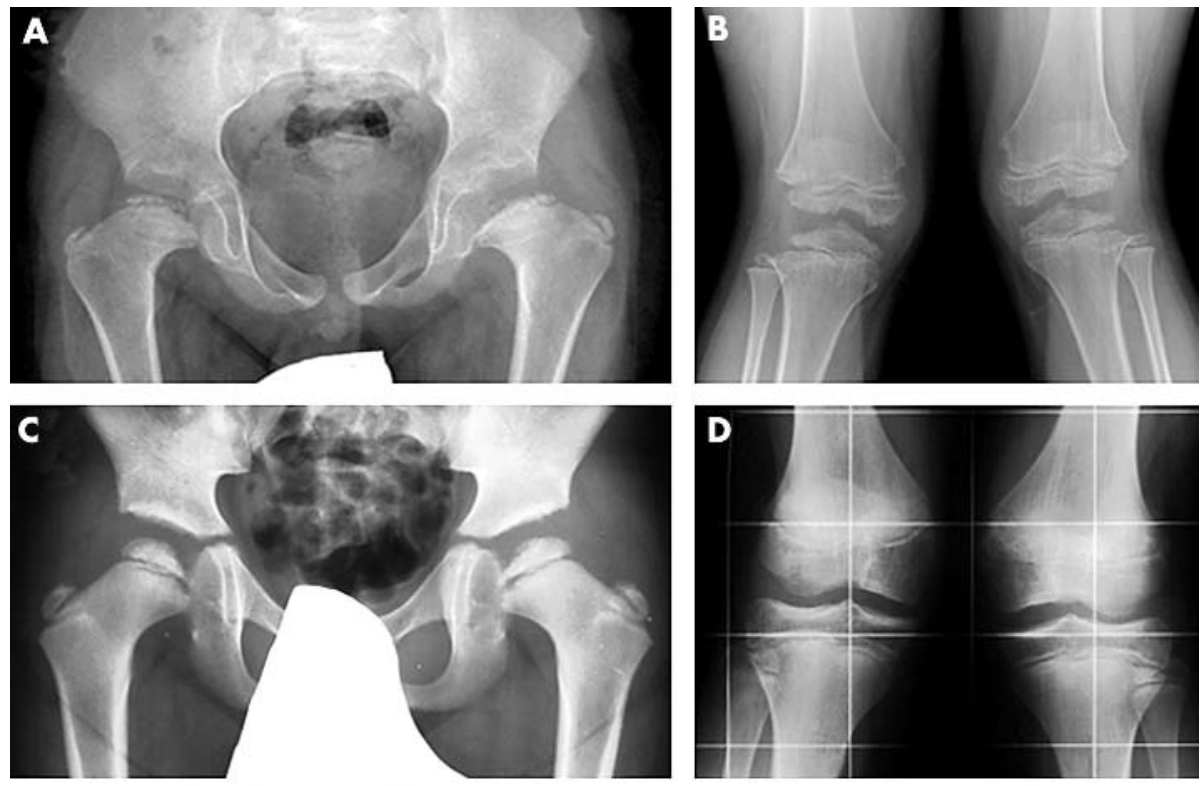

Figure 4 Anteroposterior (AP) radiographs of the hips and knees of three unrelated patients with MED that results from the R121W substitution.

$(A, B)$ Individual II-5 in family 6 at 10 years of age. The hips are characterised by bilateral coxa vara with irregular acetabulum, very small and fragmented femoral epiphyses, and short femoral necks. The knees show bilateral genu valgum with small and irregularly ossified epiphyses, metaphyseal irregularities, and bilateral ossification defect of the distomedial side of the femurs. $(C, D)$ Individual IV-2 in family 5 at 9 and 14 years of age (pelvis and knees, respectively), showing small femoral epiphyses with medial flattening at the hips and mild epiphyseal changes in the knees with bilateral genu valgum. (E,F) Individual DL (Chapman et al) ${ }^{10}$ at 10 years of age. The hips show small capital femoral epiphyses. The knee epiphyses are small with irregular contours and osteochondritis dissecans is present in
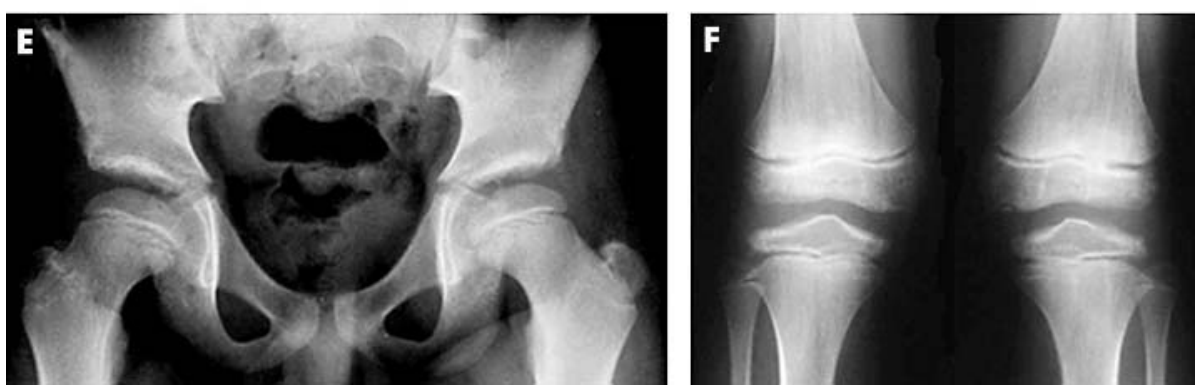
the left knee.

T303M change. Biochemical and biophysical analysis of matrilin-3 in vitro will ultimately help to determine if the E252K and T303M changes have any functional significance and may provide the rationale for a role in modifying disease severity or as susceptibility changes in these common diseases.

Considering the precise location of MATN3 mutations in the $\beta$ sheet region of matrilin-3, the overlapping expression of matrilin-3 and matrilin-1 in developing cartilage, and the observation that matrilin-3 can form hetero-oligomers with matrilin-1 both in vivo and in vitro, we were surprised when we did not identify any MED mutations in the exons encoding the A-domains of matrilin- 1 . These data might be explained by subtle differences in the temporal-spatial expression of MATN1 and MATN3. Alternatively, it remains a possibility that our patient cohort was not large enough (or did not contain the correct MED subtype) to identify a MATN1 mutation. A targeted mutation screen of MATNI in a spectrum of chondrodysplasia phenotypes including MED therefore may be required. Unfortunately no clue to a candidate phenotype was possible from the analysis of a matnl knockout mouse, in which anatomical and histological studies demonstrated normal skeletal development. ${ }^{30}$

The phenotypic spectrum of MATN3 mutations and in particular the inter-familial variability of the R121W mutation is a worthy point of discussion. Affected individuals in families 5 and 6 and in the family we have previously reported $^{10}$ all have the same missense mutation (R121W), which affects a conserved residue within the $\beta \mathrm{B}$ strand. Interestingly, the radiographic abnormalities in each of the probands from these families show significant variability and range from severe (fig $3 \mathrm{~A}, \mathrm{~B}$ ) to relatively mild (fig 2E,F) epiphyseal abnormalities in the hips and knees and overlapping with both COMP and type IX collagen related radiographic phenotypes. ${ }^{14}$ This inter-familial (and intrafamilial) variability of MED resulting from MATN3 mutations suggests that other genetic and/or environmental factors may play a role in modifying the severity of this particular form of MED. These genetic modifiers may reside in the other genes that are involved in the pathogenesis of MED such as the COMP and collagen IX genes, or alternatively they may be found in the many other genes that are involved in the coordination of endochondral ossification and joint formation.

In summary, the MATN3 mutations identified in this study confirm that abnormalities in the A-domain of matrilin-3 can result in MED, and confirm the important role that these residues play in the folding and/or function of the matrilin-3 A-domain.

\section{ACKNOWLEDGEMENTS}

We would sincerely like to thank the families for their help and interest in this study and to numerous colleagues who have provided us with patient samples. This work was supported in part by grants from the European Commission (grant QLG1-CT-2001-02188 to M D Briggs, M J Wright, L Ala-Kokko, G R Mortier, R Elles and others to support the European Skeletal Dysplasia Network (www.esdn.org); The Arthritis Research Campaign (grants B0681 and B0644 to M D Briggs); The Polish State Committee for Scientific Research (grant 3P05E00722 to M Czarny-Ratajczak); The Foundation for Paediatric Research, Helsinki, Finland and an ESPE Research Fellowship sponsored by Novo Nordisk A/S (to O Mäkitie); The Canadian Institutes of Health Research (to W G Cole); The Academy of Finland, The Arthritis Foundation, Louisiana Gene Therapy Research Consortium (New Orleans, LA, USA) and HCA-The Health Care Company (Nashville, TN, USA) (to L Ala-Kokko), and The Flanders 
Fund for Scientific Research (grant G.0013.97 to G R Mortier). M Czarny-Ratajczak is a Research Fellow of the Foundation for Polish Science, C Baldock has a Royal Society Olga Kennard Research Fellowship, and M D Briggs is a Research Fellow of the Arthritis Research Campaign.

\section{Authors' affiliations}

G C Jackson, F Barker, C Baldock, M D Briggs, Wellcome Trust Centre for Cell Matrix Research, School of Biological Sciences, University of Manchester, Manchester, UK

E Jakkula, L Ala-Kokko, Collagen Research Unit, Biocenter and Department of Medical Biochemistry and Molecular Biology, University of Oulu, Oulu, Finland

M Czarny-Ratajczak, L Ala-Kokko, Center for Gene Therapy and Department of Medicine, Tulane University Health Sciences Center, New Orleans, LA, USA

M Czarny-Ratajczak, P Rogala, Karol Marcinkowski University of Medical Sciences, Poznan, Poland

O Mäkitie, W G Cole, Hospital for Sick Children, Toronto, Ontario, Canada

M J Wright, Institute of Human Genetics, International Centre for Life, Newcastle upon Tyne, UK

S F Smithson, Department of Clinical Genetics, St Michael's Hospital, Bristol, UK

M Suri, Clinical Genetic Service, Nottingham City Hospital, Nottingham, UK

G R Mortier, Department of Medical Genetics, Ghent University Hospital, Ghent, Belgium

G C Jackson, A Wallace, R Elles, National Genetics Reference Laboratory (Manchester), Regional Genetics Service, St Mary's Hospital, Manchester, UK

Correspondence to: $\operatorname{Dr} M$ Briggs, Wellcome Trust Centre for Cell-Matrix Research, School of Biological Sciences, University of Manchester, 2.205 Stopford Building, Oxford Road, Manchester M13 9PT, UK; mike.briggs@man.ac.uk

Received 13 June 2003

Accepted 14 July 2003

\section{REFERENCES}

1 Treble NJ, Jensen FO, Bankier A, Rogers JG, Cole WG. Development of the hip in multiple epiphyseal dysplasia. Natural history and susceptibility to premature osteoarthritis. J Bone Joint Surg (Br) 1990;72:1061-4.

2 Ingram RR. Early diagnosis of multiple epiphyseal dysplasia. J Pediatr Orthop 1992; 12:241-4.

3 Haga N, Nakamura K, Takikawa K, Manabe N, Ikegawa S, Kimizuka M. Stature and severity in multiple epiphyseal dysplasia. J Pediatr Orthop 1998; 18:394-7.

4 Sheffield EG. Double-layered patella in multiple epiphyseal dysplasia: a valuable clue in the diagnosis. J Pediatr Orthop 1998;18:123-8.

5 Unger S, Hecht JT. Pseudoachondroplasia and multiple epiphyseal dysplasia: New etiologic developments. Am J Med Genet 2001;106:244-50.

6 Briggs MD, Chapman KL. Pseudoachondroplasia and multiple epiphyseal dysplasia: Mutation review, molecular interactions, and genotype to phenotype correlations. Hum Mutat 2002;19:465-78.

7 Briggs MD, Hoffman SM, King LM, Olsen AS, Mohrenweiser H, Leroy JG, Mortier GR, Rimoin DL, Lachman RS, Gaines ES, Celeniak JA, Knowlton RG, Cohn DH. Pseudoachondroplasia and multiple epiphyseal dysplasia due to mutations in the cartilage oligomeric matrix protein gene. Nat Genet 1995; 10:330-6.

8 Muragaki $Y$, Mariman EC, van Beersum SE, Perala M, van Mourik JB, Warman ML, Olsen BR, Hamel BC. A mutation in the gene encoding the alpha 2 chain of the fibril-associated collagen IX, COL9A2, causes multiple epiphyseal dysplasia (EDM2). Nat Genet 1996;12:103-5.
9 Paassilta P, Lohiniva J, Annunen S, Bonaventure J, Le Merrer M, Pai L, AlaKokko L. COL9A3: A third locus for multiple epiphyseal dysplasia. Am J Hum Genet 1999;64:1036-44.

10 Chapman KL, Mortier GR, Chapman K, Loughlin J, Grant ME, Briggs MD. Mutations in the region encoding the von Willebrand factor $A$ domain of matrilin-3 are associated with multiple epiphyseal dysplasia. Nat Genet 2001;28:393-6.

11 Czarny-Ratajczak M, Lohiniva J, Rogala P, Kozlowski K, Perala M, Carter L, Spector TD, Kolodziej L, Seppanen U, Glazar R, Krolewski J, LatosBielenska A, Ala-Kokko L. A mutation in COL9A1 causes multiple epiphyseal dysplasia: further evidence for locus heterogeneity. Am J Hum Genet 2001;69:5.

12 Superti-Furga A, Neumann L, Riebel T, Eich G, Steinmann B, Spranger J, Kunze J. Recessively inherited multiple epiphyseal dysplasia with normal stature, club foot, and double layered patella caused by a DTDST mutation. $J$ Med Genet 1999;36:621-4.

13 Ballhausen D, Bonafe L, Terhal P, Unger SL, Bellus G, Classen M, Hamel BC, Spranger J, Zabel B, Cohn DH, Cole WG, Hecht JT, Superti-Furga A. Recessive multiple epiphyseal dysplasia (rMED): phenotype delineation in eighteen homozygotes for DTDST mutation R279W. J Med Genet 2003;40:65-71.

14 Unger SL, Briggs MD, Holden P, Zabel B, Ala-Kokko L, Paassilta P, Lohiniva J, Rimoin DL, Lachman RS, Cohn DH. Multiple epiphyseal dysplasia: radiographic abnormalities correlated with genotype. Pediatr Radiol 2001;31:10-18.

15 Mortier GR, Chapman K, Leroy JL, Briggs MD. Clinical and radiographic features of multiple epiphyseal dysplasia not linked to the COMP or type IX collagen genes. Eur J Hum Genet 2001;9:606-12.

16 Segat D, Frie C, Nitsche PD, Klatt AR, Piecha D, Korpos E, Deak F, Wagener R, Paulsson M, Smyth N. Expression of matrilin-1, -2 and -3 in developing mouse limbs and heart. Matrix Biol 2000;19:649-55.

17 Zhang $Y$, Chen $Q$. Changes of matrilin forms during endochondral ossification. Molecular basis of oligomeric assembly. J Biol Chem 2000;275:32628-34

18 Deak F, Wagener R, Kiss I, Paulsson M. The matrilins: a novel family of oligomeric extracellular matrix proteins. Matrix Biol 1999;18:55-64.

19 Paulsson M, Piecha D, Segat D, Smyth N, Wagener R. The matrilins: a growing family of A-domain-containing proteins. Biochem Soc Trans 1999;27:824-6.

20 Whittaker CA, Hynes RO. Distribution and evolution of von Willebrand/ integrin a domains: widely dispersed domains with roles in cell adhesion and elsewhere. Mol Biol Cell 2002;13:3369-87.

21 Fitzgerald J, Tay Ting S, Bateman JF. WARP is a new member of the von Willebrand factor A-domain superfamily of extracellular matrix proteins. FEBS Lett 2002;517:61-6.

22 Chen Q, Zhang Y, Johnson DM, Goetinck PF. Assembly of a novel cartilage matrix protein filamentous network: molecular basis of differential requirement of von Willebrand factor A domains. Mol Biol Cell 1999;10:2149-62.

23 Makihira S, Yan W, Ohno S, Kawamoto T, Fujimoto K, Okimura A, Yoshida E, Noshiro M, Hamada T, Kato Y. Enhancement of cell adhesion and spreading by a cartilage-specific noncollagenous protein, cartilage matrix protein (CMP/Matrilin-1), via integrin alphalbetal. J Biol Chem 1999;274:11417-23

24 Wallace AJ, Wu CL, Elles RG. Meta-PCR: a novel method for creating chimeric DNA molecules and increasing the productivity of mutation scanning techniques. Genet Test 1999;3:173-83.

25 Rost B, Fariselli P, Casadio R. Topology prediction for helical transmembrane proteins at $86 \%$ accuracy. Protein Sci 1996;5:1704-18.

26 Kleemann-Fischer D, Kleemann GR, Engel D, Yates JR 3rd, Wu JJ, Eyre DR olecular properties of matrilin-3 isolated from human growth cartilage. Arch Biochem Biophys 2001;387:209-15.

27 Pan TC, Zhang RZ, Pericak-Vance MA, Tandan R, Fries T, Stajich JM, Viles K, Vance JM, Chu ML, Speer MC. Missense mutation in a von Willebrand factor type $\mathrm{A}$ domain of the alpha $3(\mathrm{VI})$ collagen gene (COL6A3) in a family with Bethlem myopathy. Hum Mol Genet 1998;7:807-12.

28 Sasaki T, Hohenester E, Zhang RZ, Gotta S, Speer MC, Tandan R, Timpl R, Chu ML. A Bethlem myopathy Gly to Glu mutation in the von Willebrand factor A domain N2 of the collagen alpha3(VI) chain interferes with protein folding. FASEB J 2000;14:761-8.

29 Stefansson SE, Jonsson H, Ingvarsson T, Manolescu I, Jonsson $\mathrm{HH}$, Olafsdottir G, Palsdottir E, Stefansdottir G, Sveinbjornsdottir G, Frigge ML, Kong A, Gulcher JR, Stefansson K. Genomewide scan for hand osteoarthritis: a novel mutation in matrilin-3. Am J Hum Genet 2003:72:1448-59.

30 Aszodi A, Bateman JF, Hirsch E, Baranyi M, Hunziker EB, Hauser N, Bosze Z, Fassler R. Normal skeletal development of mice lacking matrilin 1: redundant function of matrilins in cartilage? Mol Cell Biol 1999;19:7841-5. 